\title{
Identiteet ja agentsus kaasaegses koltasaamide rahvatantsus
}

\begin{abstract}
Petri Hoppu
Teesid: Artikkel käsitleb tantsu rolli Soomes elavate koltasaamide elus, arutledes nende ajaloo, identiteedi ja agentsuse üle. Kultuuriliselt ja keeleliselt kuuluvad koltasaamid idasaamide hõimu. Algselt asustasid nad suurt territooriumi Inari järvest ida pool, kuni Murmanskini Venemaal. Tänapäeval elab enamik neist Inari järve ümbruses Põhja-Soomes, Lapimaal, kuhu nad pärast Teist maailmasõda ümber asustati. Koltasaamide erinevad identiteedid avalduvad nii keeles, muusikas, kui ka religioonis, kuid tõenäoliselt kõige selgemalt tantsus. Nende tantsutraditsioon, eriti aga kadrill, eristab neid teistest Soome saamidest ning ühendab neid Põhja-Vene kultuuritraditsiooniga. Vaatamata dramaatilisele minevikule on koltasaamid säilitanud oma kultuuri ja omanäolise, kuid samas pidevalt muutuva etnilise identiteedi. Nende identiteedil on palju iseloomulikke jooni nii sotsiaalses kui ka personaalses ajaloos ja tantsimine on osa sellest teest, mille nad on aja jooksul läbinud.
\end{abstract}

Märksõnad: agentsus, identiteet, koltasaamid, kultuur, rahvatants

Artikkel käsitleb tantsu rolli Soomes elavate koltasaamide elus, arutledes nende ajaloo, identiteedi ja agentsuse üle. Koltasaamid ehk sä'mmlaž, nagu nad end ise nimetavad, on üks saami hõimudest, Põhja-Euroopa põlisrahvas. Nad on väike, kultuuriliselt ja keeleliselt selgelt eristuv idasaamide hõim. Saami keeled kuuluvad uurali keelte hulka ja on läänemeresoome keelte (nt soome ja eesti) kõige lähemad sugulaskeeled. Kuni 20. sajandi teise pooleni kutsuti saame tavaliselt laplasteks, kuid praegusel ajal on kasutusel nende põlisnimi saamid.

21. sajandini on säilinud kümme saami keele murret nii Norras, Rootsis, Soomes kui ka Venemaal. Paraku suri viimane akkala saami murde oskaja Venemaal umbes kümme aastat tagasi, ja paljud teised saami keele murded on samuti väljasuremisohus. Enamik veel elusolevast 700 koltasaamist elab Soomes, Inari vallas, ning ka Soome teistes piirkondades, mõned ka teisel pool Norra piiri ning ainult üksikud Venemaal. Lisaks koltasaamidele on Soomes 
veel kaks saamide hõimu selgelteristuva keelega: põhjasaamid, kes moodustavad kõige arvukama rühma, ja inarisaamid.

Traditsiooniliselt on saami majandus ja kultuur olnud seotud põhjapõtradega, kuid mitte kõik saamid ei ole olnud ega ole praegugi põhjapõdrakasvatajad (Lehtola 2002: 10). Tegelikult pole traditsioonilised elatusalad - karjatamine, kalapüük ja jahipidamine - enam ülekaalus, ja saamide majanduse struktuur nendes riikides, kus on nende asualad, sarnaneb suures osas ülejäänud rahvastiku omale. Paljud Soomes elavad saamid on kolinud Lapimaalt suurtesse linnadesse, peamiselt Helsingisse (Lehtola 2002: 86). Siiski on selge, et saamid tahavad säilitada oma identiteeti vaatamata sellele, et nad ei ela enam oma kodumaal. Nende kultuur on tänapäevases Põhjamaade ühiskonnas edasi arenenud ning saavutanud uusi vorme näiteks rahvamuusikas ja visuaalsetes kunstides.

Pärast Teist maailmasõda on saami igapäevaelu iseloomustanud pidev võitlus kultuurilise ja keelelise ellujäämise eest, ja koltasaamide jaoks on see olukord olnud iseäranis karm. Saami identiteeti puudutavad arutelud on tänapäeva Soomes eriti kirglikud, ning need on seotud peamiselt põlisrahvaste õigusi tagava rahvusvahelise ILO 169 konventsiooni ratifitseerimise küsimustega. Konventsioon tunnistab, et põlisrahvaste kultuur ja identiteet, mis erineb põhirahvastiku omast, moodustab nende elu lahutamatu osa, ning neid erinevusi tuleb austada, tunnustades nende traditsioone, keelt ja uskumusi (vt nt ILO Convention No. 169, dateerimata). Pärast aastatepikkust arutelu tegi Soome valitsus lõpuks 2011. aastal otsuse konventsiooni toetada. Paraku otsustas Soome parlament 13. märtsil 2015. aastal ILO 169 konventsiooni mitte ratifitseerida, kuid see jäeti siiski päevakorda hilisemateks arutlusteks ("Finland shelves indigenous rights agreement ratification", YLE 2015). Selle tulemusena pöördusid Soome saami parlament ja kolm Soomes tegutsevat saami organisatsiooni 2015. aasta aprillis Ühinenud Rahvaste Organisatsiooni poole abipalvega oma õiguste kaitsmiseks (Finland's Sámi request UN help in securing their rights, YLE 2015b).

Käesoleva artikli eesmärk on leida koltasaamide näitel uusi identiteedi ja agentsuse määratlemise viise vähemusrahvuste kultuuritegevuses, mis toimub aktiivselt nende eluviisi osana. Uurimismaterjalina on kasutatud arvukalt allikmaterjali arhiividokumentidest ja kirjandusest kuni autori enda poolt kogutud etnograafilise materjali ja kogemusteni Põhja-Soomest. Analüüs põhineb teatud määral seoseanalüüsil, mis rõhutab seoseid teksti ja tegevuse vahel (vt Lane 2014). 


\section{Üleminekuaja identiteedid}

Selleks et mõista keerulist olukorda, milles saamid ja nende hulgas ka koltasaamid täna elavad, peame uurima identiteete protsessi seisukohast. See eeldab, et me vaatleme identiteeti pidevalt loodava ja taasloodavana, muutumas ajas ja ajaloos. Saami uurija Rauna Kuokkanen on öelnud, et saami identiteete iseloomustab rändamine (Lehtola 2002: 86). See sarnaneb Stuart Halli (1996: 4) arvamusega, kes rõhutab inimeste teekonda, erinevaid punkte, mis on neid toonud praegusesse aega, uurimaks oma identiteete. Need teekonnad hoiavad inimesi kohal, aga mitte ühes ja samas kohas. Halli arvamuse kohaselt on identiteedid seotud ajaloo-, keele- ja kultuuriressursside kasutamisega pigem kellekski saamise, mitte aga olemise protsessis: tähtis pole mitte see, kes me oleme, vaid pigem see, kelleks me võime saada, kuidas meid presenteeritakse, ja mil moel see mõjutab viisi, kuidas me ennast võime presenteerida.

Sarnaselt Halli vaadetele väidab Homi Bhabha, et identiteete ei saa omistada ettemääratud etnilisele või märgistatud kultuurile, mida iseloomustavad stabiilsed ja muutumatud traditsioonid. Bhabha arvates hõlmavad kultuuriidentiteediga seotud arutlused püsivat kokkupuutepunkti ja kultuurisündmuste vahetamist, mis omakorda tekitavad vastastikust ja muutustele aldist arusaamist kultuuride erinevustest. Bhabha väidab ka, et täieõiguslik võim hübriidkultuurses keskkonnas "ei sõltu traditsiooni püsivusest; selle allikaks on traditsiooni jõud, mida jäädvustatakse võimalikkuse ja vastuolulisuse kaudu" (Bhabha 1994: 2-5).

Birgitta Frello (2006: 1) märgib aga, et on tähtis tõstatada küsimus sellest, kes räägib hübriidsusest, mil määral seda mõistet kasutatakse ja milliste teiste mõistetega see seondub. Frello (2006: 10) väitel on poliitilised vihjed tihedalt seotud ühest küljest hübriidsuse ja teisest küljest puhtuse mõistega, ning see seob neid kultuurilise distantsi määratlemise ja mõistelise tõlgendamisega. Oluline osa hübriidsuse mõistele pühendatud arutlustest seondub sellega, kuidas agentsust kultuurilise puhtuse ja ebapuhtuse määratlemisel ja levitamisel seadustatakse.

Identiteet on tihedalt seotud agentsuse küsimusega. Carl Ratner väidab, et agentsus ei seondu individuaalse valikuga, vaid on kultuuriline ja sotsiaalne nähtus, mis põhineb sotsiaalsetel suhetel. Ratneri arvamuse kohaselt on agentsus ajalooline projekt, kuna seda on vaja ellu viia ja täiustada ajalooliste protsesside kaudu. See ei pea tingimata olema loominguline või aktiivne, kuid on võimalik, et ta selleks muutub (Ratner 2000: 423). See võib toimuda, kui kasutada kultuurilisi või sotsiaalseid strateegiaid, mis aitavad inimgruppidel end määratleda viisil, mis toetab nende agentsuse säilitamist. 
Ühe sellise strateegia kasutuselevõtjaks oli Gayatri Spivak (1988), ning hiljem hakati seda nimetama strateegiliseks essentsialismiks, mis viitab sellele, et see võib olla kasulik marginaliseeritud gruppidele lihtsustamaks nende kollektiivset identiteeti, et aidata neil saavutada teatud sotsiaalseid ja poliitilisi tulemusi. Strateegilise essentsialismi mõistet on peamiselt uuritud kui vähemuse strateegiat peavoolu ühiskonna mõjutamiseks. Selles tähenduses eeldab strateegiline essentsialism, et inimgrupid, kuigi nad on heterogeensed, võivad teadlikult pidada oluliseks ja isegi ühtlustada oma ühiskondlikku kuvandit, selleks et teatud eesmärkide saavutamiseks oma grupiidentiteeti lihtsustatult ja kollektiivselt edasi arendada. See on miski, mida paljud vähemusrühmad - näiteks setod, kveenid või Soome rootslased - tegelikult teevad: nad määratlevad teatud kultuurinähtusi nagu rahvarõivad, murded, või muusika-ja tantsutraditsioonid, kuna nende arvates on neil nähtustel muutumatu ja ajatu sisu. See on teatud määral riskantne, sest see võib anda eelise nendele, kelle essentsialism ületab nende mõjupiirid, nagu näiteks teadlased, kunstnikud, poliitikud või vallutajad (Eide 2010: 76).

Küsimus sellest, kellel on õigus kultuuri defineerida, on kindlasti seotud võimuga. Strateegiline essentsialism pakub ühe lahenduse, misläbi inimesed võivad saavutada agentsuse (tegevusvõimekuse) tänu kultuurilisele paigalseisule, kuid see tõstatab küsimusi agentsuse seaduslikkusest ning ka selle päritolust ja muutustest kultuuri kaitsmise ja säilimise kontekstis. Alternatiivse strateegiana võib agentsuse rolli identiteetide käsitlemisel näha kui sotsiaalsete representatsioonide esindajat või mahasurujat (Phelps \& Nadim 2010: p. 13.3). Selline lähenemine rõhutab põhiolemuse asemel strateegilisi arutlusi kultuuri kujundamise ja säilimise osana ning tagab vahendid kultuuri säilitamiseks kiirelt muutuvas ja globaliseeruvas maailmas.

Koltasaamide identiteete võib vaadelda kui protsessi, mis peegeldab selle rahvusrühma ajaloolisi ja kultuurilisi juuri. Ei ole olemas ja pole ka kunagi olnud ühtainust koltasaami identiteeti; pigem on koltasaamide erinevad identiteedid punktiks, kus kohtuvad ja segunevad subjektiivsed ja kollektiivsed ajalood ja kogemused. Nende identiteedid on liikunud väga konkreetseid teid mööda: oma algsel asualal, mis praegusel ajal kuulub põhiliselt Venemaale, liikusid nad aastaringselt, rännates talveküladest kevad-, suve- ja sügisküladesse, ja lõpuks jälle tagasi talveküladesse. Laiaulatuslik migratsiooniprotsess leidis aga aset Teise maailmasõja ajal ja sõjajärgsel perioodil, kui nad sunniti oma algselt asualalt lõplikult lahkuma. Tänapäeva ühiskonnas toimub uutmoodi ränne Lapimaalt Soome lõunapiirkondadesse. 


\section{Koltasaamide tantsukultuur}

Koltasaamide kultuurilugu iseloomustavad tihedad kontaktid venelastega. 16. sajandist alates kuni aastani 1920 oli enamik koltasaame Venemaa võimu all ning näiteks vene õigeusk ja kirik on isegi tänasel päeval koltasaamide ühiskonna ja kultuuri lahutamatu osa. Veelgi enam, koltasaamidel on rikkalik pärimusmuusika traditsioon: leuddid ja itkud, saamikeelse nimega reäkk, samuti teised laulud, milles avalduvad mõjutused erinevatest piirkondadest, eriti Venemaalt, kuid ka Soomest, Norrast ja Karjalast. Leuddid moodustavad koltasaamide muusikatraditsiooni kõige silmapaistvama osa. Need on eepilised laulud, mis kirjeldavad inimese elus toimuvaid sündmusi. Tavaliselt on need elu kõrghetked, nagu näiteks abieluettepaneku tegemine või abiellumine. Kuigi leudde esitatakse sageli mina-vormis, viitavad need harva laulja enda läbielamistele. Leuddid on äärmiselt kollektiivse iseloomuga ja enamik neist räägib inimestest või juhtumistest, kes või mis on kogukonnas tuntud (Jouste 2006: 295-297).

See, mis teeb koltasaamid teiste Soome ja Skandinaavia saamide hõimude seas unikaalseks, on nende tantsud. Koltasaamid on tantsinud rahvalikke paaris- ja rühmatantse, nii seltskonna- kui ballitantse, alates 19. sajandi teisest poolest. Paljude kirjelduste põhjal võib öelda, et kui nad elasid oma talvekülades algsel asualal, oli tantsimine nende jaoks meelelahutuse väga tähtis vorm. Koltasaamide tantsukultuuril on palju ühisjooni Karjala ja Põhja-Venemaa tantsukultuuridega, ja mõningal määral isegi põhja-soomlastega. Siiski on ilmne, et põhiosa nende pärimustantsudest, kui mitte kõik, on pärit Vene Karjalast ja Venemaalt. Sarnased tantsud on tuntud ka Koola poolsaarel elavate teiste saami hõimude juures.

Kadrill, mida tantsitakse nelinurgas, on koltasaamide kõige tuntum tants, mis oli äärmiselt populaarne kuni Teise maailmasõjani. Sõjajärgsel perioodil tantsiti seda mõningal määral veel kuni 1950. aastateni (Niemeläinen 1983: 35). Koltasaamide kadrillil on kuus tuuri ja seda tantsivad neli paari. Sestjorkka on samuti nelinurkse joonisega tants, kuid see on kadrillist üsna erinev. Tantsu alguses seisavad neli tantsijat nelinurkselt. Nad hakkavad liikuma kaheksakujuliselt nagu riilis. Iga kord, kui nad oma kohale tagasi pöörduvad, paluvad nad kedagi käest kinni võttes tantsuga ühineda. Tantsu jooksul moodustub tantsijatest neli rida, mis katkematult liiguvad. Samuli Paulaharju (2009: 51), kes on kirjeldanud üht koltasaamide tantsuüritust, on maininud ka tantsu nimega ristisiirre, kuid selle tantsu kohta puudub detailsem informatsioon. 


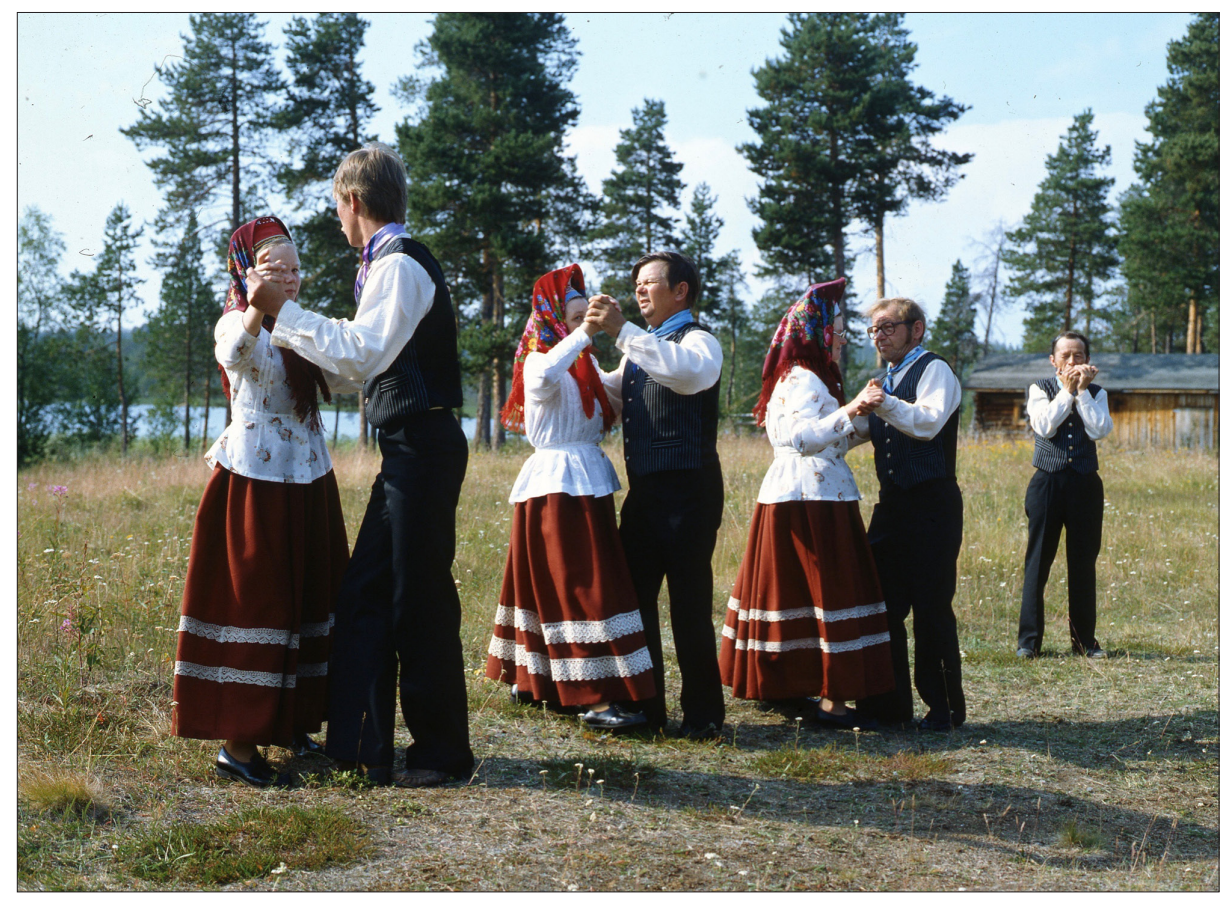

Foto 1. Koltasaamid tantsimas karoobuškat Nellimi külas. Urho Pietilä foto 1983.

Dokumenteeritud paaristantsud (nt kerenski, padespann, oira, karoobuška) pärinevad 19. sajandi lõpust ja 20. sajandi algusest, enamik neist on valsi või tuustepi (ingl. two-step) variandid. Nagu ka kadrill, pärinevad need tantsud Venemaalt ja paljud neist olid tuntud ka Soomes ja Karjalas ning samuti Finnmarkis, Norra kõige põhjapoolsemas maakonnas (nt Rausmaa \& Rausmaa 1977; Malmi 1993; Bakka \& Wikan 1996). Need tantsud koosnevad tavaliselt kahest või kolmest osast ja lõppevad paaride pöörlemise või ringis ettepoole liikumisega.

Kadrillist - ehk rohkem kui mõnest teisest koltasaamide tantsust - on saanud nende etnilise identiteedi iseloomulik sümbol, mida on dokumenteerinud mitmed autorid ja etnograafid alates 20. sajandi algusest. Ühe kõige värvikama kirjelduse on kirja pannud rootslane Robert Crottet (1908-1987), kes elas 1930. aastate lõpus koltasaamide juures Petšengas ja sõjajärgsel perioodil Inari vallas. Tema kirjelduse võib leida raamatus Lapplands andra ansikte (Crottet 1966: 93-95). 


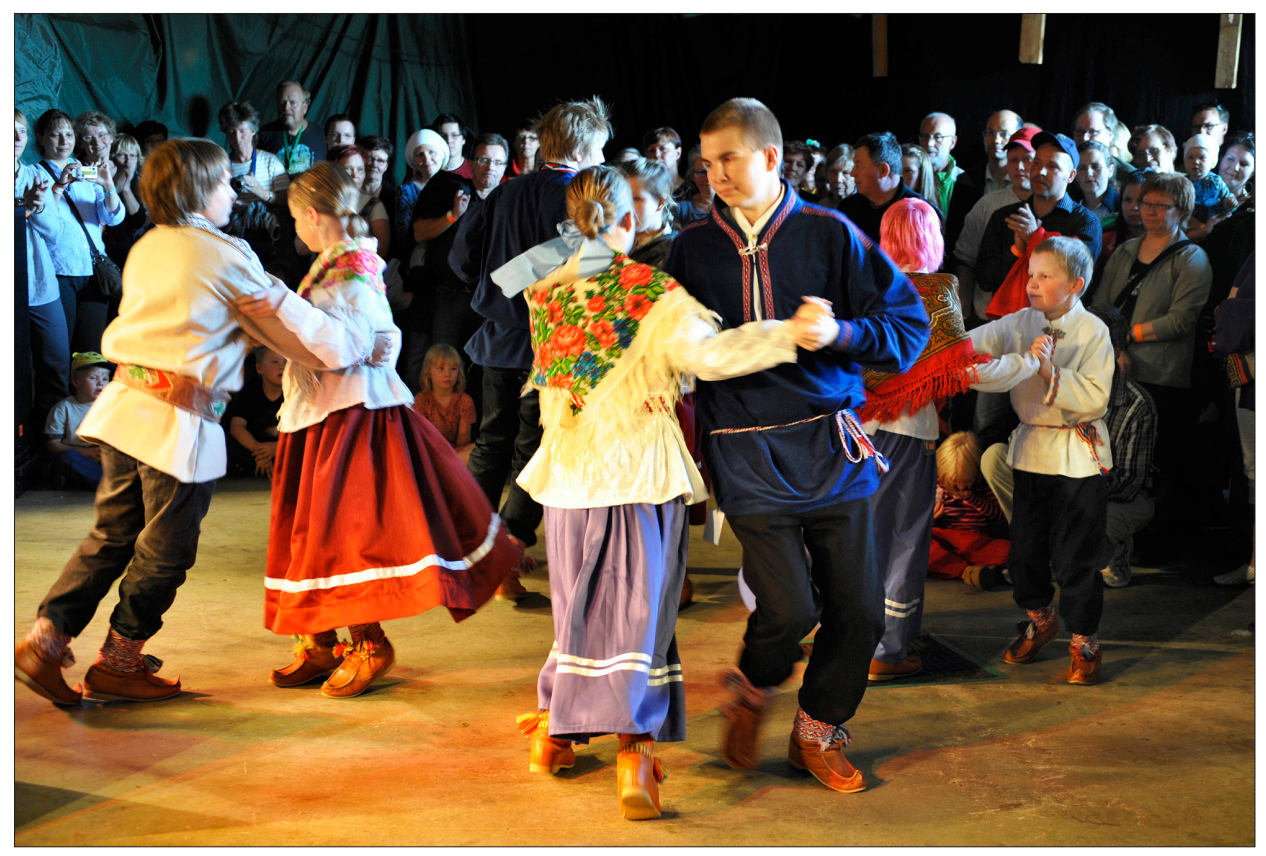

Foto 2. Koltasaami lapsed kadrilli tantsimas. Inari 2009. Harri Nurmineni foto 2009.

Kuni 1920. aastateni ja Suonikyläs isegi kuni Teise maailmasõjani oli talvekülades veedetud periood lõbustuste aeg. Soome etnograaf Samuli Paulaharju külastas koltasaamide külasid 1914. aastal ja kirjeldas, kuidas talvekuudel korraldasid noored peaaegu igal õhtul tantsupidusid, kogunedes üksteise kodudesse ja tantsides varaste hommikutundideni. Kõige lustlikum aeg oli nädal enne paastuaega: tants, joomine, laulmine ja põdrarakenditega saanisõit kestis ööpäev läbi (Paulaharju 2009: 51). Paastuaegsel perioodil, nagu paljudes teistes Ida-Euroopa piirkondades, ei olnud tantsimine lubatud, ja peagi pärast lihavõttepühi lahkusid koltasaamid talveküladest, et rännata oma kevadistesse ja suvistesse elupaikadesse. Seega polnud tantsimiseks sobilik periood eriti pikk, kuid mil iganes võimalik, tehti seda suure entusiasmiga. 


\section{Hajutamine ja ümberasustamine}

Koltasaamide algne asuala koosnes seitsmest külast (siida), mis asusid peamiselt praegusel Venemaa territooriumil, kuid osaliselt ka Norras ja Soomes. Nagu eespool öeldud, põhines nende igapäevaelu ja majandus aastaringsel rändemudelil. Algselt määratlesid sellise rändetsükli kalastusvõimalused; põhjapõtrade karjatamine sobitati hiljem kalastustegevusega ("From Petsamo to Inari", Siida 2003). Kuna Lapimaal, saamide asualal, puudusid kehtestatud piirid kuni 18. sajandini, võisid koltasaamid aastasadu vabalt oma suguvõsa maadel ringi rännata. 1852. aastal suleti aga Norra ja Venemaa vaheline piir, mis jättis ühe koltasaamide siida Norra poolele ja katkestas külaelanike sidemed teiste koltasaamidega (Linkola \& Sammallahti 1995: 48-51).

Järgmine tähelepanuväärne sündmus leidis aset 1920. aastal, kui kirjutati alla Soome ja Nõukogude Venemaa vaheline Tartu rahuleping. Selle lepingu kohaselt tõmmati piir sirge joonena läbi koltasaamide asuala: kolm siidat jäid Soome võimupiirkonda ja kolm Venemaa territooriumile. Pärast 1920. aastat oli ainult Suonjeli siida koltasaamidel võimalik oma rändemudelit järgida ning liikuda ringi oma traditsioonilistes piirkondades - talve-, kevad-, suve- ja sügiskülades - isegi kui küla oli osa oma põlistest maadest kaotanud. Kaks koltasaamide küla Soome poolel - Paatsjoki ja Petsamo - jäid kaitsetusse olukorda. Traditsioonilised elatusallikad kadusid ja elanikud pidid kohanema uue ühiskonna väärtuste ja tavadega (Lehtola 2002: 66). Nõukogude Liidus hävitas kollektiviseerimisprotsess koltasaamide traditsioonilise ühiskonna, kui kõik saamid asustati ümber üheteistkümnesse kolhoosi koos sama piirkonna teiste elanikega (Mustonen \& Mustonen 2011: 88).

Teine maailmasõda laostas lõpuks ka Soome koltasaamide elu. Vastavalt Moskva (1944) ja Pariisi (1947) rahulepingutele loovutati koltasaamide asualad Nõukogude Liidule. Koltasaamid evakueeriti esmalt Soome keskpiirkondadesse, kuid mõne aasta pärast asustati nad oma algse asuala lähedusse, Inari valla idaossa, Nellimi, Keväjärvi ja Sevettijärvi-Näätämö piirkonda.

\section{Marginaliseerimisest strateegilise essentsialismini}

Uutel asualadel ei olnud koltasaamidel võimalik oma traditsioonilist aastaringset rännet jätkata ning selle tagajärjeks olid tähelepanuväärsed muutused elatusallikates võrreldes Petšenga ajaga. Samuti hakkasid vanade asualade kaotamisega hääbuma ka paljud koltasaamide traditsioonid, kaasa arvatud tantsimine. Inari vallas kannatasid koltasaamidest uustulnukad Soome põlisrahva diskrimineerimise all; sama juhtus ka teiste saami hõimudega, nagu näi- 
teks inari-ja põhjasaamidega, kes elasid samas piirkonnas. Kui ma 2014. aasta augustis Inaris kohalikke koltasaame intervjueerisin, räägiti mulle, et näiteks Nellimi külas oli koltasaamidel kõigi etniliste rühmade seas kõige madalam ühiskondlik positsioon.

Siiski hakkas 1970. aastatel koltasaamide vaim ja etniline uhkus tugevnema tänu saami kultuuri taassünnile; võeti kasutusele koltasaami ortograafia, organiseeriti keeletunde ja trükiti raamatuid koltasaami kirjakeeles. Koltasaamide traditsioone, nagu näiteks käsitööd, tantse ja muusikat, õpetati ja anti edasi noorematele põlvkondadele ("The Skolt Sámi today", Siida 2003/2009). Lõpuks, pärast Nõukogude Liidu lagunemist 1990. aastate alguses, taastati pärast seitsekümmend aastat kestnud lahusolekut sidemed Koola poolsaare saamidega (Katrillin pyörteissä, dateerimata).

Pärast saami "renessanssi" 1970. aastatel hakkasid saamid aktiivselt oma tantsukultuuri taaselustama. Intervjueeritavatelt saadud andmete kohaselt asutati sel ajal kaks kollektiivi - Sevettijärvi küla kadrillirühm ja Nellimi küla folkloorirühm. Need kollektiivid esinesid kohalikel pidustustel ja samuti mujal toimuvatel folkloorifestivalidel. Näiteks võis koltasaame 1970., 1980. ja 1990. aastatel tihti kohata rahvusvahelistel pärimusmuusikafestivalidel Kaustises, kõige suuremal Soomes toimuval festivalil omasuguste seas. Tantsude taaselustamise esimeses faasis oli enamik tantsijatest sündinud Petšengas, kuid ainult kõige vanemad neist olid neid tantse oma nooruses ka ise tantsinud; ülejäänud olid neid õppinud kui rahvatantse sõjajärgsel perioodil.

Neil kümnenditel dokumenteeriti koltasaamide pärimustantse ka detailsemalt. Pirkko-Liisa Rausmaa, Soome folklorist ja rahvatantsu-uurija, ning tema kehalise kasvatuse õpetajast abikaasa Esko Rausmaa ja etnomusikoloog Heikki Laitinen salvestasid koltasaamide tantse nende kodukülades ja samuti Kaustise pärimusmuusikafestivalil 1978. ja 1979. aastal. Neid materjale säilitatakse Soome Kirjanduse Seltsi arhiivis Helsingis ja Pärimusmuusika Instituudi arhiivis Kaustises.

Seda faasi võib iseloomustada Spivaki mõistega 'strateegiline essentsialism'. 1970. ja 1980 aastatel toetasid seda ideoloogilist seisukohta paljud teadlased, kes kartsid, et koltasaamide kultuuriväljundit võivad kuritarvitada näiteks Soome folkloorirühmad. Kui etnomusikoloogid ja folkloristid dokumenteerisid koltasaamide muusikat ja tantse, siis lisati kuritarvituste ärahoidmiseks materjalide juurde märkus, et neid ei või kasutada folkloristlikel eesmärkidel. See keeld kehtib tänaseni Soome Kirjanduse Seltsi arhiivis, kus asub enamik materjalidest.

Alates 1970. aastatest kuni sajandi lõpuni võtsid eelmainitud kaks rühma endale vastutuse koltasaamide tantsude säilitamise eest. Nende kollektiivide repertuaar ja koosseis peegeldas nende koltasaamide tausta, kes olid kolinud 
vastavatesse küladesse: Sevettijärvi koltasaamid pärinesid põhiliselt Suonikyläst ja Nellimi koltasaamid Petsamost ja Paatsjoest. Sevettijärvi kadrillirühm esitas peaaegu eranditult kadrille, mis oli kõige populaarsem tants Suonikyläs, samas kui Nellimi folkloorirühm tantsis erinevaid paaristantse, mis olid tavapärased nende kodukülades Petšengas. Nellimi folkloorirühma endine juht, üks minu intervjueeritavatest Inaris, rääkis mulle, et nad olid teadlikult otsustanud kadrilli mitte tantsida, vaatamata sellele, et paljud tantsijad mäletasid seda oma lapsepõlvest ja noorusest.

Selline strateegiline essentsialistlik ideoloogia viis teatud vastuoludeni esinevate rühmade vahel ja sees, eriti kui kaasatud olid mitte-koltasaamid ja mittesaamidest osalejad. Näiteks tahtis Soome Saami Nõukogu teada kõigi Nellimi folkloorirühma tantsijate ja muusikute tausta, kui neid 1980. aastatel välismaale esinema kutsuti. Kuna koltasaamid olid Nellimis vähemusrahvus, vajas rühm mittekoltasaamidest liikmeid, et nende tantse esitada. Sel põhjusel arvasid mõned saami võimuesindajad, et rühma ei saa välismaale saata kui koltasaamide kultuuri esindajat.

\section{Tegevusvajadus}

21. sajandisse jõudmine on toonud koltasaamide ühiskonda ja kultuuri järjekordseid suuri muutusi. Petšengas sündinud põlvkond on peaaegu täielikult surnud. Nooremad põlvkonnad ei sea endale enam eesmärgiks säilitada koltasaamide kultuuri nii, nagu see oli Petšengas, vaid nad otsivad uusi viise leppimaks nii oleviku kui ka minevikuga. Tantsimine ja eriti kadrill on muutunud tänapäeva koltasaamide kultuuri sümboolseks osaks, ja otsustades selle ümber toimuvate arvukate tegevuste järgi näib, et koltasaamide noorem põlvkond tunnetab oma kultuuri püsimajäämist ning tänu sellele vaatavad nad uutmoodi oma tantsuajaloole ning laiemas plaanis ka kultuuriloole.

Selle asemel, et hoida kinni essentsialistlikust ideoloogiast, arendavad saamid tänapäeval uusi kultuuri hübriidvorme, sulatades kokku näiteks koltasaamide laulu traditsioonilisi vorme ja rokkmuusikat. Kadrilli tantsimine ei piirdu enam ainult folkloorsete etendustega, vaid seda õpetatakse koltasaami lastele Sevettijärvi algkoolis ning samuti paljudel kursustel, ning mitte ainult koltasaamidele, vaid kõigile, kes soovivad seda õppida, mis oleks kolmkümmend aastat tagasi olnud täiesti mõeldamatu. Nii näiteks oli kadrill üks teemadest 2012. aasta juunis Inaris toimunud rahvusvahelise koltasaami keele ja kultuuri konverentsi töötubades (Sanila 2012), ning 2014. aasta septembris korraldati kadrilliõppimise kursused Soome pealinnas Helsingis (Moshnikoff 2014). See 
on andnud kadrillile uue elu ja muutnud selle tantsu teistsuguseks, kuid samas on ta siiski seotud sellega, mida tantsisid eelmised põlvkonnad.

Võib öelda, et tänapäevases identifitseerimisprotsessis on kadrill saavutanud koltasaamide seas teatud elujõulise sümboli seisundi. Isegi taaselustatud vormis peetakse koltasaamide kadrilli kohaliku ajaloo kehastuseks, mis taotleb autentsust läbi oma edastamisviisi (vt Buckland 2006: 16). Koltasaamid peavad kadrilli osaks oma kultuurist, ja kuigi seda on välja tõrjutud ja ümber paigutatud, jätkab ta eksisteerimist uutes kontekstides. Veelgi enam, tõsiasi, et kadrilli peetakse sama sümboolseks kui koltasaami murret ja leuddi, annab tunnistust sellest, et seda hinnatakse kõrgelt.

\section{Kokkuvõtteks}

Koltasaamide hübriidkultuuri identiteet areneb aja kulgedes. Nende kultuuri piirid muutuvad pidevalt seoses nende ajaloo ja kaasaegse Soome ühiskonna arengutega. Ian M. Clothier (2005) väidab, et hübriidkultuurid võivad endas sisaldada erinevaid kultuurimõjusid ja kuna nende piiridel toimub aktiivne lõikumine ja kattumine, võivad nad kergesti luua vahepealseid identiteete, mis on iseloomulikud ka tänapäeva koltasaamidele.

Seega käsitlevad koltasaamid oma tantsu ajalugu ja kultuuri uutest vaatenurkadest, seda ümber kirjutades ja sulandades oma kaasaegsetesse hübriididentiteetidesse. See uus strateegia ei hõlma endas üksnes traditsioonide kaitset, vaid annab koltasaamidele ka võimaluse jõuda kokkuleppele nii oma ajaloo kui ka kaasaegse ühiskonnaga. Selle tulemusena ja vaatamata oma dramaatilisele minevikule, diasporaale ja diskrimineerimisele uutel asualadel on koltasaamidel õnnestunud säilitada oma eriline, samas pidevalt muutuv etniline identiteet, ning seejuures tõmmata tähelepanu ka oma kultuurile, kaasa arvatud tantsud. Nende identiteedil on palju iseloomulikke jooni nii sotsiaalses kui personaalses ajaloos ja tantsimine on osa sellest teest, mille nad nende kogemustega on läbinud.

\section{Kommentaar}

Artikkel on edasiarendus 14. septembril 2015 Tallinna Ülikooli rahvusvahelisel konverentsil "Eesti kultuuri suurpeod maailmapärandis" tehtud ettekandest. 


\section{Kirjandus}

Bakka, Egil \& Wikan, Arne 1996. Dansetradisjoner fra Finnmark. Finnmark Ungdomslag og Rådet for folkemusikk og folkedans.

Bhabha, Homi K. 1994. The Location of Culture. London: Routledge.

Buckland, Theresa Jill 2006. Dance, History, and Ethnography. Buckland, Theresa Jill (toim). Dancing from Past to Present. Nation, Culture, Identities 3-24. Madison, Wisconsin: The University of Wisconsin Press.

Clothier, Ian M. 2005. Created Identities: Hybrid Cultures and the Internet. Convergence: The International Journal of Research into New Media Technologies, 11, lk 44-59 (doi: 10.1177//1354856505061053).

Crottet, Robert 1966. Lapplands andra ansikte. Stockholm: LTs förlag.

Eide, Elisabeth 2010. Strategic Essentialism and Ethnication. Hand in Glove? Nordicom Review, 31 (2), lk 63-78 (https://oda.hio.no/jspui//bitstream/10642/588/2/511697. pdf - 3. aprill 2016).

Frello, Birgitta 2006. Cultural Hybridity - Contamination or Creative Transgression? AMID Working Paper Series 54. Akademiet for Migrationsstudier i Danmark (http:// www.amid.dk/pub/papers/AMID_54-2006_Birgitta_Frello.pdf - 3. aprill 2016).

Hall, Stuart 1996. Who Needs 'Identity'? Hall, Stuart \& Gay, Paul du (toim). Questions of Cultural Identity. London: Sage, lk 1-17.

ILO = ILO Convention No. 169 (dateerimata). Pro 169 (http://pro169.org/ilo-169/ 3. aprill 2016).

Jouste, Marko 2006. Suomen saamelaisten musiikkiperinteet. Asplund, Anneli \& Hoppu, Petri \& Laitinen, Heikki \& Leisiö, Timo \& Saha, Hannu \& Westerholm, Simo (toim). Suomen musiikin historia. Kansanmusiikki. Helsinki: WSOY, lk 272-307.

Katrillin pyörteissä (dateerimata). Saa'mi nue'tt (http://www.saaminuett.fi/kolttasaamelaiset/ kulttuuri/katrillin-pyorteissa.html - 3. aprill 2016).

Lane, Pia 2014. Nexus analysis. Östman, Jan-Ola \& Verschueren, Jef (toim). Handbook of Pragmatics Online (DOI: 10.1075/hop.18.nex1).

Lehtola, Veli-Pekka 2002. The Sámi People - Traditions in Transition. Tõlkinud Linna Weber Müller-Wille. Aanaar: Kustannus-Puntsi.

Linkola, Martti \& Sammallahti, Pekka 1995. Koltanmaa, osa Saamenmaata. Saarinen, Tuija \& Suhonen, Seppo (toim). Koltat, karjalaiset ja setukaiset. Pienet kansat maailmojen rajoilla. Kuopio: Snellman-instituutti, lk 39-57.

Malmi, Viola 1993. Karjalaisen kansantanssin lähteillä. Helsinki: Vapaan Sivistystoiminnan Liitto. 
Moshnikoff, Minna 2014. Helsingissä tanssittiin katrillia. Saa'mi nue'tt (http://oddaz. saaminuett.fi/2014/09/21/helsingissa-tanssittiin-katrillia/ - 3 aprill 2016).

Mustonen, Tero \& Mustonen, Kaisu 2011. Eastern Sámi Atlas. Tampere: Snowchange.

Niemeläinen, Päivyt 1983. Suomalainen kansantanssi. Niemeläinen, Päivyt (toim). Suomalainen kansantanssi. Helsinki: Otava, lk 19-51.

Paulaharju, Samuli 2009. Kolttain mailta. Parandatud väljaanne [1. väljaanne 1921]. Helsinki: SKS.

Phelps, Joshua M. \& Nadim, Marjan 2010. Ideology and agency in ethnic identity negotiation of immigrant youth. Papers on Social Representations 19, lk 13.1-13.27 (http:// www.psych.lse.ac.uk/psr/PSR2010/19_13Phelps.pdf - 3. aprill 2016).

Ratner, Carl 2000. Agency and Culture. Journal for The Theory of Social Behavior 30, lk 413-434 (http://lchc.ucsd.edu/mca/Paper/00_01/agency.htm - 3. aprill 2016).

Rausmaa, Pirkko-Liisu \& Rausmaa, Esko (toim) 1997. Tanhuvakka. Suuri suomalainen kansantanssikirja. Helsinki: WSOY.

Sanila, Tanja 2012. Koltansaamen kielen ja kulttuurin konferenssi 14.-15.6.2012. Saa'mi nue'tt. (http://oddaz.saaminuett.fi/2012/06/01/koltansaamen-kielen-ja-kulttuurinkonferenssi-14-15-6-2012-2/ - 3. aprill 2016).

Siida 2003 = From Petsamo to Inari. Siida (http://www.samimuseum.fi/saamjiellem/ english/historia.html - 3. aprill 2016).

Siida 2003/2009 = The Skolt Sámi Today. Siida (http://www.samimuseum.fi/saamjiellem/ english/nykypaiva.html - 3. aprill 2016).

Spivak, Gayatri Chakravorty 1988. Subaltern Studies: Deconstructing Historiography. Guha, Ranaijt \& Spivak, Gayatri Chakravorty (toim). Selected Subaltern Studies. New York and Oxford: Oxford University Press, lk 3-32.

YLE 2015a = Finland shelves indigenous rights agreement ratification. YLE Uutiset 14.03.2015 (http://yle.fi/uutiset/finland_shelves_indigenous_rights_agreement_ratification/7868419 _ 3. aprill 2016).

YLE 2015b = Finland's Sámi request UN help in securing their rights. YLE Uutiset 29.04.2015 (http://yle.fi/uutiset/finlands_sami_request_un_help_in_securing_their_rights/7961531 _ 6. aprill 2016). 


\title{
Summary
}

\section{Identity and agency in contemporary Skolt Sámi folk dance}

\author{
Petri Hoppu
}

Keywords: agency, culture, folk dance, identity, Skolt Sámi

This article examines the role of dance of the Skolt Sámi in Finland in negotiating their history, identity and agency. The Skolt Sámi are a culturally and linguistically distinct group of the Eastern Sámi. Originally, they lived in a wide area, from Lake Inari eastward to the Russian city of Murmansk. Today, most Skolts live near Lake Inari in Finnish Lapland, where they were relocated after World War II. The multiple identities of the Skolts are actualized in many ways, in language, music, religion, but perhaps most distinctively in their dancing. Their dancing traditions, especially the quadrille, separate them from other Sámi in Finland and connect them to Northern Russian culture. Despite their dramatic past, the Skolts have preserved their culture and distinctive, yet ever-changing ethnic identities. Their identities are characterized by many points in their social and personal histories, and dancing is a part of the routes they have traveled within these experiences. 